\title{
Male-female estimates of feminine assertiveness related to females' clothing styles
}

\author{
ED M. EDMONDS, DELWIN D. CAHOON, and ELIZABETH HUDSON \\ Augusta College, Augusta, Georgia
}

\begin{abstract}
Men and women college students rated the perceived assertiveness of a female model dressed either in conservative clothing or in clothing judged to be sexually provocative in both sexual and nonsexual social situations. No differences related to clothing style were found, and all of the students rated the model as being more assertive in sexual interactions than in nonsexual interactions. The female students rated the model as more assertive relative to the rating she was given by the male students. The results are discussed with respect to gender differences concerning culturally defined femininity.
\end{abstract}

Several studies have examined male-female differences with respect to gender-related attitudes and behavior. Abbey (1982), for example, found that men often misinterpret women's friendly behavior as an indication of sexual interest. Women also appear to misperceive the attitudes and intentions of men toward women. Cahoon and Edmonds (1989) found that women judged men as viewing women more negatively than was actually the case. This bias was especially apparent in the women's overestimation of men's motivation to rape. With respect to sex-role stereotyping, women also estimate that men are more negatively biased toward women than is indicated by the opinions actually expressed by men (Edmonds, Cahoon, \& Shipman, 1991).

Gender has also been considered with respect to perceptions of socially assertive behavior. Kelly, Kern, Kirkley, Patterson, and Keane (1980) reported that assertive people are seen as more skilled and competent than nonassertive people but are viewed as less likable. In addition, assertive females were evaluated less favorably than assertive males. Kern (1982) found that although assertive persons were seen as more competent and less desirable than nonassertive persons, assertive females were not rated less positively than assertive men. In contrast, Schroeder, Rakos, and Moe (1983) found that assertive females were rated more positively than were assertive males.

Men and women raters have been found to differ in the ways they evaluate males and females who behave assertively. Kelly et al. (1980) reported that females tended to rate unassertive women as more thoughtful, tactful, and unassertive than they were rated by men; however, the female raters perceived the assertive women to be less desirable than the unassertive women. Possibly, the personal attributes of the rater are more important than gender in evaluations of assertiveness. Gormally (1982), in a study in which all subjects were female, found that as-

Correspondence should be addressed to Delwin D. Cahoon, Department of Psychology, Augusta College, Augusta, GA 30910. sertive persons tended to rate assertive behavior more positively. Kern (1982) found that both male and female subjects generally devalued social responses not consistent with their own behavior. In a later study (Kern, Cavell, \& Beck, 1985), these results were reconfirmed, indicating that the attitudes and values of the observer influence the evaluation of assertion.

Abbey, Cozzarelli, McLaughlin, and Harnish (1987) investigated sex differences related to perceptions of women with differing clothing styles. In general, women wearing relatively revealing clothing styles were rated as more assertive, whereas women wearing nonrevealing clothing styles were rated, by females, as being more sincere. Edmonds and Cahoon (1986) and Cahoon and Edmonds (1989) reported a generally negative bias toward women wearing provocative clothing; these women were seen as being more likely to be raped or mugged.

In the present study, male and female observers were asked to rate the probable refusal assertiveness of a female subject, dressed either conservatively or in a sexually provocative manner, in interactions judged to be either sexual or nonsexual.

\section{METHOD}

Seventy-six undergraduates ( 26 males and 50 females) enrolled in introductory psychology classes were shown one of two slides. One slide depicted a model wearing a revealing dress that might be considered provocative; the other slide featured a model wearing a blouse and skirt that we judged to be somewhat conservative. The pictures were cropped at neck level to minimize facial cues, and poses in the two slides were similar. The students were asked to rate, on a 7-point scale, the models' refusal assertiveness in a variety of sexual or nonsexual interactions involving the model and other people. The students received no special incentive to participate in the study.

\section{RESULTS AND DISCUSSION}

The data were analyzed by means of a $2 \times 2 \times 2$ repeated measures analysis of variance. The between-subject factors were sex of rater and style of clothing. The withinsubject factor was sexual versus nonsexual social inter- 
action. No significant differences were found between clothing styles. However, the sex of rater and type of social interaction main effects were significant. The females rated the model as more assertive relative to the rating she was assigned by the males $[F(1,72)=5.615, p<.019]$, whereas both the males and the females rated the model as being more assertive in sexual interactions than in nonsexual interactions $[F(1,72)=17.082, p<.001]$.

The results of the present study did not confirm the study by Abbey et al. (1987), in which females wearing revealing clothing were viewed as relatively assertive. As noted above, however, the female students participating in this study rated the model as more assertive relative to the rating she was given by the male students. Perhaps this is related to the increased attention given in relatively recent years to the presumed desirability of increased assertiveness by women, with a corresponding proliferation of assertiveness training opportunities. In this sense, men may suffer more from a "cultural lag" with respect to the prevalence of assertive behavior among females. Another possibility is that men and women have differing views pertaining to females' role in the society, with men valuing female conformity and passivity to a greater extent than do women. Kern et al. (1985) have suggested that the best predictors of reactions toward assertiveness in females may be represented by attitudes toward women.

All of the subjects rated the model as being more assertive in sexual-social interactions than in nonsexual interactions. This may be related to cultural acceptance of the belief that females need not submit to sexual advances contrary to their wishes. Therefore, assertiveness in this particular area may be considered appropriate even by those who feel that, in general, females should be docile and conforming. In addition, sexual refusal assertion might be expected to have high personal relevance for the college-age females in this study. This factor may have influenced the female subjects to perceive assertiveness in sexual interactions to a relatively greater extent than did the male subjects.
Assertiveness is a problematic research area because of difficulties in defining the construct and in the identification of potentially relevant variables (Kern, 1982; Schroeder et al., 1983). Further research efforts are to be encouraged, however, in view of the great personal and social significance of assertive behavior.

\section{REFERENCES}

ABBEY, A. (1982). Sex differences in attribution for friendly behavior: Do males misperceive females' friendliness? Journal of Personality \& Social Psychology, 42, 830-838.

Abbey, A., Cozzarelu, C., Mclaughun, K., \& Harnish, R. (1987). The effects of clothing and dyad sex composition on perceptions of sexual intent: Do women and men evaluate these cues differently? Journal of Applied Social Psychology, 17, 108-126.

CaHoOn, D. D., Edmonds, E. M. (1989). Male-female estimates of opposite-sex first impressions concerning females' clothing styles. Bulletin of the Psychonomic Society, 27, 280-281.

EDMONDS, E. M., \& CAHOON, D. D. (1986). Attitudes concerning crimes related to clothing worn by female victims. Bulletin of the Psychonomic Society, 24, 444-446.

Edmonds, E. M., Cahoon, D. D., Shipman, M. (1991). Predictions of opposite-sex attitudes concerning gender-related social issues. Bulletin of the Psychonomic Society, 29, 295-296.

Gormally, J. (1982). Evaluation of assertiveness: Effects of gender, rater involvement and level of assertiveness. Behavior Therapy, 13, 219-225.

Kelly, J., Kern, J., Kirkley, B., Patterson, J., \& Keane, T. (1980). Reactions to assertive versus unassertive behavior: Differential effects for males and females and implications for assertiveness training. Behavior Therapy, 11, 670-682.

KERN, J. (1982). Predicting the impact of assertive, empathic-assertive, and nonassertive behavior: The assertiveness of the assertee. Behavior Therapy, 13, 486-498.

Kern, J., CAvell, T., \& Beck, B. (1985). Predicting differential reactions to males' versus females' assertions, empathic-assertions, and nonassertions. Behavior Therapy, 16, 63-75.

SCHROEDER, H., RAKOS, R., \& MOE, J. (1983). The social perception of assertive behavior as a function of response class and gender. $B e$ havior Therapy, 14, 534-544.

(Manuscript received October 4, 1991.) 